Among the remaining papers read were:--" Science as a Subject in Girls" Schools," by Miss F. E. Hunt ; "The Curriculum of Secondary Education," by D. H. Hollidge; "The Technical Element in a State System of Education," by Antony St. Ledger; "A Contribution towards the Study of the Relation of Ethics and Science," by the Rev. J. S. Pollock; "The Importance of Mental Science as a Guide in Primary Education," by James Rule.

The business of the Association concluded with a meeting of the General Council, at which the following recommendations, among others, were adopted :-

(I) That the committee for the investigation of the thermodynamics of the voltaic cell be reappointed without grant.

(2) That the report of the Seismological Committee be printed, and that the committee be reappointed and allowed a grant of fIo towards the cost of the erection of the instruments presented by Dr. Von Rebeur-Paschwitz at Timaru.

(3) That the following be a committee-namely, Messrs. F. M. Bailey, R. L. Jack, A. Gibb Maitland, A. Meston, C. W. De $\mathrm{Vis}$, and $\mathrm{H}$. Tryon-to investigate the geology, land flora, and natural resources generally of the islands and islets of the Great Barrier Reef.

(4) That the New Zealand Government be asked to set apart Stephen's Island, Cook Strait, as a reserve for the Tuatara Lizard.

(5) That the committee for the investigation of glacial deposits in Australasia be Messrs. Hutton, R. L. Jack, R. Tate, R. M. Johnston, F. W. E. David (secretary), G. Sweet, J. Shirley, W. Houchins, E. G. Hogg, E. J. Dunn, A. Montgomery, and E. F. Pittman.

(6) That a committee-consisting of Messrs. H. C. Stanley, A. B. Brady, Thomas Parker, Prof. Warren, Prof. Kernot, Henry Moncrieff, and James Fincham-be appointed to inquire into the habits of the teredo, and the best means of preserving timber or structures subject to the action of tidal waters.

(7) That the committee on psycho-physical research be appointed without a grant.

The next meeting of the Association will be held at Sydney in I 897, under the presidency of Prof. Liversidge, and the following meeting will take place at Melbourne.

\section{ELECTRIFICATION OF AIR, AND THERMAL CONDUCTIVITY OF ROCK AT DIFFERENT TEMPERATURES.*}

\section{(I.) "ON THE ELECTRIFICATION OF AIR."}

$\S \mathrm{I}$. CONTINUOUS observation of natural atmospheric electricity has given ample proof that cloudless air at moderate heights above the earth's surface, in all weathers, is electrified with very far from homogeneous distribution of electric density. Observing, at many times from May till September, I859, with my portable electrometer on a flat open sea-beach of Brodick Bay in the Island of Arran, in ordinary fair weather at all hours of the day, I found the difference of potentials, between the earth and an insulated burning match at a height of 9 feet above it ( 2 feet from the uninsulated metal case of the instrument, held over the head of the observer), to vary from 200 to 400 Daniell's elements, or as we may now say volts, and often during light breezes from the east and north-east, it went up to 3000 or 4000 volts. In that place, and in fair weather, I never found the potential other than positive (never negative, never even down to zero), if for brevity we call the earth's potential at the place zero. In perfectly clear weather under a sky sometimes cloudless, more generally somewhat clouded, I often observed the potential at the 9 feet heigh to vary from about 300 volts gradually to three or four times that amount, and gradually back again to nearly the same lowe value in the course of about two minutes. $t$ I inferred that these gradual variations must have been produced by electrified masse of air moving past the place of observation. I did not remark then, but I now see, that the electricity in these moving masse of air must, in all probability have been chiefly positive to cause the variations which I observed, as I shall explain to you a little later.

* Two communications to the Philosophical Society of Glasgow meeting in the Natural Philosophy Lecture-room of the University of Glasgow, March 27, "On the Electrification of Air": "On the Thermal Conductivity 0 1Rock at different temperature." 280.

NO. I 333, VOL 52 ]
\$2. Soon after that time a recording atmospheric electrometer * which I devised, to show by a photographic curve the continuous variation of electric potential at a fixed point, was established at the Kew Meteorological Observatory, and has been kept in regular action from the commencement of the year I86I till the present time. It showed incessant variations quite of the same character, though not often as large, as those which I had observed on the sea-beach of Arran.

Through the kindness of the Astronomer Royal, I am able to place before you this evening the photographic curves for the year 1893 , produced by a similar recording electrometer which has been in action for many years at the Royal Observatory Greenwich. They show, as you see, not infrequently, during several hours of the day or night, negative potential and rapid transitions from large positive to large negative. Those were certainly times of broken weather, with at least showers of rain, or snow, or hail. But throughout a very large proportion of the whole time the curve quite answers to the description of what I observed on the Arran sea-beach thirty-six years ago, except that the variations which it shows are not often of so large amount in proportion to the mean or to the minimums.

8 3. Thinking over the subject now, we see that the gradual variations, minute after minute through so wide a range as the 3 or 4 to I, which I frequently observed, and not infrequently rising to twenty times the ordinary minimum, must have been due to positively electrified masses of air, within a few. hundred feet of the place of observation, wafted along with the gentle winds of 5 or 10 or 15 feet per second which were blowing at the time. If any comparably large quantities of negatively electrified air had been similarly carried past, it is quite certain that the minimum observed potential, instead of being in every case positive, would have been frequently large negative.

$\$ 4$. Two fundamental questions in respect to the atmospheric electricity of fair weather force themselves on our attention :(I) What is the cause of the prevalent positive potential in the air near the earth, the earth's potential being called zero? (2) How comes the lower air to be electrified to different electric densities whether positive ornegative in different parts? Observations and laboratory experiments made within the last six or eight years, and particularly two remarkable discoveries made by Lenard, which I am going to describe to you, have contributed largely to answering the second of these questions.

$\$ 5$. In an article "On the Electrification of $\Lambda$ ir by a Waterjet," by Magnus Maclean and Makita Goto, $\uparrow$ experiments were described showing air to be negatively electrified by a jet of water shot vertically down through it from a fine nozzle into a basin of water about 60 centimetres below it. It seemed natural to suppose that the observed electrification was produced by the rush of the fine drops through the air ; but Lenard conclusively proved, by elaborate and searching experiments, that it was in reality due chiefly, if not wholly, to the violent commotions of the drops impinging on the water surface of the receiving basin, and he found that the negative electrification of the air was greater when they were allowed to fall on a hard slab of any material thoroughly wetted by water, than when they fell on a yielding surface of water several centimetres deep. He had been engaged in studying the great negative potential which had been found in air in the neighbourhood of waterfalls, and which had generally been attributed to the inductive action of the ordinary fine weather electric force, giving negative electricity to each drop of water-spray before it breaks away from conducting communication with the earth. Before he knew. Maclean and Goto's paper, he had found strong reason for believing that that theory was not correct, and that the true explanation of the electrifica tion of the air must be found in some physical action not hitherto discovered. A less thorough inquirer might have been satisfied with the simple explanation of the electricity of waterfalls naturally suggested by Maclean and Goto's result, and might have rested in the belief that it was due to an electrifying effect produced by the rush of the broken water through the air; but Lenard made an independent experimental investigation in the Physical Laboratories of Heidelberg and Bonn, by which he learned that the seat of the negative electrification of the air electrified is the lacerated water at the foot of the fall, or at any rocks against which the water impinges, and not the multitudinous interfaces between air and water falling freely in drops through it.

$\$ 6$. It still seems worthy of searching inquiry to find

\footnotetext{
* "Electrostatics and Magnetism" xvi. \$\$ 271, 292.

+ Fhilosophical Magazine, 1890, second half-year.
} 
electrification of air by water falling in drops through it, even though we now know that, if there is any such electrification, it is not the main cause of the great negative electrification of air which has been found in the neighbourhood of waterfalls. For this purpose an experiment has been very recently made by Mr. Maclean, Mr. Galt, and myself, in the course of an investigation regarding electrification and diselectrification of air with which we have been occupied for more than a year. The apparatus which we used is before you. It consists of a quadrant electrometer connected with an insulated electric filter * applied to test the electrification of air drawn from different parts of a tinned iron funnel, I 87 centimetres long and 15 centimetres diameter, fixed in a vertical position with its lower end open and its upper end closed, except a glass nozzle, of $1 \cdot 6 \mathrm{~mm}$. aperture, admitting a jet of Glasgrow supply water (from Loch Katrine) shot vertically down along its axis. The electric filter ( $R$ in the drawing), a simplified and improved form of that described in the Proceedings of the Royal Society for March 21, consists of twelve circles of fine wire gauze rammed as close as possible together in the middle of a piece of block tin pipe of $\mathrm{I} \mathrm{cm}$. bore and $2 \mathrm{~cm}$. length.

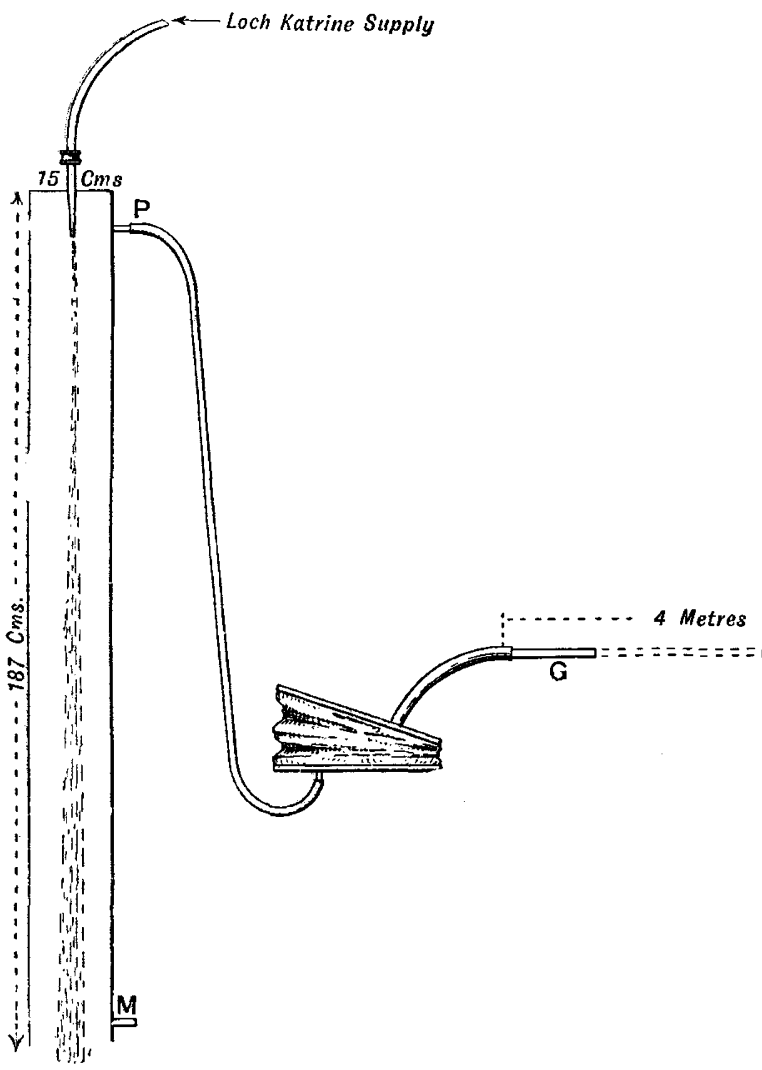

One end of it is stuck into one end of a perforation through a block of paraffin, $\mathrm{K}$, which supports it. The other end $\left(\mathrm{G}^{\prime}\right)$ of this perforation is connected by block tin pipe (which in the apparatus actually employed was 4 metres long, but might have been shorter), and india-rubber tubing through bellows to one or other of two short outlet pipes ( $M$ and $P$ ) projecting from the large funnel.

§. We first applied the india-rubber pipe to draw air from the funnel at the upper outlet, $\mathbf{P}$, and made many experiments to test the electricity given by it to the receiving filter, $R$, under various conditions as to the water-jet; the bellows being worked as uniformly as the operator could. When the water fell fairly through the funnel with no drops striking it, and through $90 \mathrm{~cm}$. of free air below its mouth, a small negative electrification of $R$ was in every case observed (which we thought might possibly be attributable to electrification of the air where the water was caught in a basin about $90 \mathrm{~cm}$. below the mouth of the funnel).

* Kelvin, Maclean, Galt, "On the Diselectrification of Air." Proc. Roy. Soc., March 14, 1895 .

NO. I 333 , VOL. 52$]$
But when the funnel was slanted so that the whole shower of drops from the jet, or even a small part of it, struck the inside of the funnel, the negative electrification of $\mathrm{k}$ was largely increased. So it was also when the shower, after falling freely down the middle of the funnel, impinged on a metal plate in metallic communication with the funnel, held close under its mouth, or Io or $20 \mathrm{~cm}$. below it. For example, in a series of experiments made last Monday (March 25), we found 28 of a volt in I 5 minutes with no obstruction to the shower ; and 4.18 volts in five minutes, with a metal plate held three or four centimetres below the mouth of the funnel; the air being drawn from the upper outlet (P). Immediately after, with $\mathrm{P}$ closed, and air drawn from the lower outlet (M), but all other circumstances the same, we found 20 of a volt in five minutes with no obstruction; and 6.78 volts in five minutes with the metal plate held below the mouth as before.

$\S 8$. These results, and others which we have found, with many variations of detail, confirm, by direct test of air drawn away from the neighbourhood of the waterfall through a narrow pipe to a distant electrometer, Lenard's conclusion that a preponderatingly strong negative electrification is given to the air at every place of violent impact of a drop against a water-surface, or against a wet solid. But they do not prove that there is no electrification of air by drops of water falling through it. We always found, in every trial, decisive proof of negative electrification; though of comparatively small amount when there was no obstruction to the shower between the mouth of the funnel and the catching basin $90 \mathrm{~cm}$. below it. We intend to continue the investigation, with the shower falling freely far enough down from the mouth of the funnel to make quite sure that the air which we draw off from any part of the funnel is not sensibly affected by impact of the drops on anything below.

$\S 9$. The other discovery * of Lenard, of which I told you, is that the negative electrification of air, in his experiments with pure water, is diminished greatly by very small quantities of common salt dissolved in it, that it is brought to nothing by 'or I per cent. ; that positive electrification is produced in the air when there is more than oI I per cent. of salt in the water, reaching a maximum with about 5 per cent. of salt, when the positive electrical effect is about equal to the negative effect observed with pure water, and falling to I4 per cent. of this amount when there is 25 per cent. of salt in the solution. Hence sea-water. containing as it does about 3 per cent. of common salt, may be expected to give almost as strong pusitive electrification to air as pure water would give of regative in similar circumstances as to commotion. Lenarc infers that breaking waves of the sea must give positive electricity to the ai over them ; he finds, in fact, a recorded observation by Exner, on the coast of Ceylon, showing the normal positive electric potential of the air to be notably increased by a storm at sea. I believe Lenard's dis covery fully explains also some very interesting observations of atmospheric electricity of my own, which I described in a letter to Dr. Joule, which he published in the Proceedings of the Literary and Philosophical Society of Manchester for October I8, I859.† "The atmospheric effect ranged from $30^{\circ}$ to about $420^{\circ}$ [of a heterostatic torsion electrometer of 'the divided-ring' species] during the four days which I had to test it ; that is to say, the electrometric force per foot of air, measured horizontally from the side of the house, was from 9 to above I 26 zinc-copper water cells. The weather was almost perfectly settled, either calm, or with slight east wind, and in greneral an easterly haze in the air. The electrometer twice within half an hour went above $420^{\circ}$, there being at the time a fresh temporary breeze from the east. What I had previously observed regarding the effect of east wind was amply confirmed.

* "Ueber die Electricität der Wasserfälle." Table xvii. p. 628. Annalen der Physik und Chemie, $189^{2}$, vol. xlvi.

$\dagger$ Republished in "Electrostatics and Magnetism." "Atmospheric Electricity," xvi. \$ 262 . 
Invariably the electrometer showed very high positive in fine weather, before and during east wind. It generally rose very much shortly before a slight puff of wind from that quarter, and continued high till the breeze would begin to abate. I never once observed the electrometer going up unusually high during fair weather without east wind following immediately. One evening in August I did not perceive the east wind at all, when warned by the electrometer to expect it; but I took the precaution of bringing my boat up to a safe part of the beach, and immediately found by waves coming in that the wind must be blowing a short distance out at sea, although it did not get so far as the shore. .... On two different mornings the ratio of the house to a station about sixty yards distant on the road beside the sea was .97 and 96 respectively. On the afternoon of the rith instant, during a fresh temporary breeze of east wind, blowing up a little spray as far as the road station, most of which would fall short of the house, the ratio was 1.08 in favour of the house electrometer-both standing at the time very high the house about $350^{\circ}$. I have little doubt but that this was owing to the negative electricity carried by the spray from the sea, which would diminish relatively the indications of the road electrometer."

\& 10. The negative electricity spoken of in this last sentence, " as carried by the spray from the sea," was certainly due to the inductive effect of the ordinary electrostatic force in the air close above the water, by which every drop or splash breaking away from the surface must become negatively electrified; but this only partially explains the difference which I observed between the road station and the house station. We now know, by the second of Lenard's two discoveries, to which I have alluded, that every drop of the salt water spray, falling on the ground or rocks wetted by it, must have given positive electricity to the adjoining air. The air, thus positively electrified, was carried towards and over the house by the on-shore east wind which was blowing. Thus, while the road electrometer under the spray showed less electrostatic force than would have been found in the air over it and above the spray, the house electrometer showed greater electrostatic force because of the positively electrified air blown over the house from the wet ground struck by the spray.

\& II. The strong positive electricity, which, as described in my letter to Joule, I always found in Arran with east wind, seemed at first to be an attribute of wind from that quarter. But I soon found that in other localities east wind did not give any very notable augmentation, nor perhaps any augmentation at all, of the ordinary fair weather positive electric force, and for a long time I have had the impression that what I observed in this respect, on the sea-beach of Brodick Bay in Arran, was really due to the twelve nautical miles of sea between it and the Ayrshire coast east-north-east of it ; and now it seems to me more probable than ever that this is the explanation when we know from Lenard that the countless breaking waves, such as even a gentle east wind produces over the sea between Ardrossan and Brodick, must every one of them give some positive electricity to the air wherever a spherule of spray falls upon unbroken water. It becomes now a more and more interesting subject for observation (which I hope may be taken up by naturalists having the opportunity) to find whether or not the ordinary fine weather positive electric force at the sea coast in various localities is increased by gentle or by strong winds from the sea, whether north, south, east or west of the land.

\& 12. From Lenard's investigation we now know that every drop of rain falling on the ground or on the sea, ${ }^{*}$ and every drop of fresh water spray of a breaking wave, falling on a fresh water lake, sends negative electricity from the water surface to the air; and we know that every drop of salt water, falling on the sea from breaking waves, sends positive electricity into the air from the water surface. Lenard remarks that more than two-thirds of the earth's surface is sea, and suggests that breaking sea-waves may give contributions of positive electricity to the air which may possibly preponderate over the negative electricity given to it from other sources, and may thus be the determining cause of the normal fair weather positive of natural atmospheric electricity. It seems to me highly probable that this preponderance is real for atmospheric electricity at sea. In average weather, all the year round, sailors in very small vessels are more wet by sea-spray than by rain, and I think it is almost certain that more positive electricity is given to the air by breaking waves than

* "Ueber die Electricität der Wasserfälle." Annalen der Physik und Chemie, $\mathrm{r}_{92}$, vol. xlvi. p. $6_{3 \mathrm{I}}$.

NO. I 333 , VOL. 52$]$ negative electricity by rain. It seems also probable that the positive electricity from the waves is much more carried up by strong winds to considerable heights above the sea, than the negative electricity given to the air by rain falling on the sea the greater part of which may be quickly lost into the sea, and but a small part carried up to great heights. But it seems to me almost certain that the exceedingly rapirl recovery of the normal fair weather positive, after the smaller positive or the negative atmospheric electricity of broken weather, which was first found by Beccaria in Italy 120 years ago, and which has been amply verified in Scotland and England, ${ }^{*}$ could not be accounted for by positively electrified air coming from the sea. Even at Beccaria's Observatory, at Garzegna di Mondovi in Pieclmont, or at Kew, or Greenwich, or Glasgow, we should often have to wait a very long time for reinstatement of the normal positive after broken weather, if it could only come in virtue of positively electrified air blowing over the place from the sea ; and several days, at least, would have to pass before this result could possibly be obtained in the centre of Europe.

$\$$ I3. It has indeed always seemed to me probable that the rain itself is the real restorer of the normal fair weather positive. Rain or snow, condensing out of the air high up in the clouds, must itself, I believe, become negatively electrified as it grows, and must leave positive electricity in the air from which it falls. Thus rain falling from negatively electrified air would leave it less negatively electrified, or non-electrified or positively electrified ; rain falling from non-electrified air would leave it positively electrified ; and rain falling from positively electrified air would leave it with more of positive electricity than it had before it lost water from its composition. Several times within the last thirty years I have made imperfect and unsuccessful attempts to verify this hypothesis by laboratory experiments, and it still remains unproved. But $\mathrm{I}$ am much interested just now to find some degree of observational confirmation of it in Elster and Geitel's large and careful investigation of the electricity produced in an insulated basin by rain or snow falling into it, which they described in a communication published in the Sitzungsberichte of the Vienna Academy of Sciences, of May 1890 . They find generally a large electrical effect, whether positive or negative, by rain or snow falling into the basin for even so short a time as a quarter of a minute, with however, on the whole, a preponderance of negative electrification.

§ 14. But my subject this evening is not merely natural atmospheric electricity, although this is certainly by far the most interesting to mankind of all hitherto known effects of the electrification of air. I shall conclude by telling you very briefly, and without detail, something of new experimental results regarding electrification and diselectrification of air, found within the last few months in our laboratory here by $\mathrm{Mr}$. Maclean, Mr. Gait, and myself. We hope before the end of the present session of the Royal Society to be able to communicate a sufficiently full account of our work.

\$15. Air blown from an uninsulated tube, so as to rise in bubbles through pure water in an uninsulated vessel, and carried through an insulated pipe to the electric receiving filter, of which I have already told you, gives negative electricity to the filter. With a small quantity of salt dissolved in the water, or sea water substituted for fresh water, it gives positive electricity to the air. There can be no doubt but these results are due to the same physical cause as Lenard's negative and positive electrification of air by the impact of drops of fresh water or of salt water on a surface of water or wet solid.

\$16. A small quantity of fresh water or salt water shaken up vehemently with air in a corked bottle electrifies the air, fresh water negatively, salt water positively. A "Winchester quart" bottle (of which the cubic contents is about two litres and a half), with one-fourth of a litre of fresh or salt water poured into it, and closed by an india-rubber cork, serves very well for the experiment. After shaking it vehemently till the whole water is filled with fine bubbles of air, we leave it till all the bubbles have risen and the liquid is at rest, then take out the cork, put in a metal or india-rubber pipe, and by double-acting bellows, draw off the air and send it through the electric filter. We find the electric effect, negative or positive according as the water is fresh or salt, shown very decidedly by the quadrant electrometer : and this, even if we have kept the bottle corked for two or three minutes after the liquid has come to rest before we take ont the cork and draw off the air.

$\$ 17$. An insulated spirit lamp or hydrogen lamp being con-

$$
\text { * "Electrostatics and Magneticm," xvi. } \$ 28 \% \text {. }
$$


nected with the positive or with the negative terminal of a little Voss electric machine, its fumes (products of combustion mixed with air) sent through a block-tin pipe, four metres long, and one centimetre bore, ending with a short insulating tunnel of paraffin and the electric filter, gives strong positive or strong negative electricity to the filter.

\$ I8. Using the little biscuit-canister and electrified needle, as described in " our communication" * to the Royal Society " On the Diselectrification of Air," but altered to have two insulated needles with varied distances of from half a centimetre to two or three centimetres between them, we find that when the two needles are kept at equal differences of potential positive and negative, from the enclosing metal canister, little or no electrification is shown by the electric filter ; and when the differences of potential from the surrounding metal are unequal, electrification, of the same sign as that of the needle whose difference of potential is the greater, is found on the filter.

When a ball and needle-point are used, the effect found depends chiefly on the difference of potentials between the needle-point and the surrounding canister, and is comparatively little affected by opposite electrification of the ball. When two balls are used, and sparks in abundance pass between them, but little electricity is deposited by the sparks in the air, even when one of the balls is kept at the same potential as the surrounding metal. [The communication was illustrated by a repetition of some of the experiments shown on the occasion of a Friday evening lecture + on Atmospheric Electricity at the Royal Institution on May I8, 1860 , in which one half of the air of the lecture-room was electrified positively, and the other half negatively, by two insulated spirit lamps mounted on the positive and negative conductors of an electric machine.]

\section{(2) "ON THE THERMAL CONDUCTIVITY OF ROCK AT DIFFERENT TEMPERATURES."}

Experiments by Lord Kelvin and Mr. Erskine Murray were described, and the apparatus used in them was shown, by which it was found that the thermal conductivity of specimens of slate, sandstone, and granite is less at higher temperatures than at lower for each of these rocks. The last tested was Aberdeen granite, for which experiments of fairly satisfactory accuracy showed the mean conductivity for the range from $146^{\circ} \mathrm{C}$. to $215^{\circ} \mathrm{C}$. to be 86 per cent. of the mean conductivity in the range from $81^{\circ} \mathrm{C}$. to $146^{\circ} \mathrm{C}$. They hope to send a communication to the Royal Society describing their work before the end of the present session.

KEIVIN.

\section{UNIVERSITY AND EDUCATIONAL INTELLIGENCE.}

OXFoRD.--Mr. D. R. Pike, of the Charterhouse, has been elected to an open Exhibition in Natural Science at Jesus College, and Mr. L. C. W. Brigstocke, of Haverfordwest Grammar School, has been elected to a Welsh Foundation Scholarship in Natural Science at the same College.

Open Scholarships and Exhibitions in Natural Science have been announced for competition at Merton College, New College, Magdalen College, and Corpus Christi College. Particulars may be obtained on application to the Dean in any of these Colleges.

CAMBRIDGE.- - The Walsinghan Medal for an original monograph on a botanical, geological, zoological, or physiological subject will be awarded in the Michaelmas Term. Essays are to be sent to Prof. Newton by October ro, 1895. Candidates must be B.A.'s not of standing to take the M.A. degree.

The subiect for the Adams Prize of 1897 is connected with Bessel's Functions. It is set forth in the University Reporter for May 14. The prize is of the value of about 6197 . It is open to all graduates of the University. Essays are to be sent to the Vice-Chancellor by December i6, I 896 .

THE Association of Technical Institutions has endeavoured to induce the Science and Art Department to discontinue the examinations now held in practical inorganic and organic chemistry, and to award attendance grants for instruction in those subjects, the amount of such grants to be dependent upon the report of the Department's inspectors on the efficiency of the equipment and teaching. The Association has received a reply to the effect

$$
\begin{aligned}
& \text { * Proceedings of the Royal Society, March } 14,1895 . \\
& + \text { "Electrostatics and Magnetism," xvi, } \$ \$ 285,286 .
\end{aligned}
$$

NO. I 333 , VOL. 52$]$ that it is not possible for the Department to comply with their request. A new syllabus for practical inorganic chemistry will appear, however, in the forthcoming edition of the Science and Art Directory, and there seems little doubt that the instruction will be so arranged in it as to make it possible to coordinate more closely the laboratory and lecture work in that subject, and afford the same latitude to teachers as is given by the new Regulations for Organised Science Schools.

\section{SCIENTIFIC SERIALS.}

American Journal of Mathematics, vol. xvii. No. 2 (Baltimore, April I895). - A method for calculating simultaneously all the roots of an equation, is a paper by Dr. E. McClintock, which was read before the American Mathematical Society on August I4 and October 27, 1894. It opens with the application to an example employed by Spitzer and by Jelinek. The calculations of these mathematicians can only be done for a pair of roots at a time, and that with considerable difficulty. The method employed by our author is fairly facile. Very little has hitherto been done in the direction of this memoir, which is one of great value in the subject of algebraic equations. The writer discusses eleven examples at length, the highest degreed equation being one of the sixth degree in $x$.--Sur le logarithme de la fonction gamma, by Hermite, is a note upon Raabe's integral, in continuation of an article in the Math. Annalen (4I, p. 58I). Sur la pression dans les milieux diélectriques ou magnétiques, by Prof. P. Duhem, corrects an error in his "Leçons sur l'Electricité et le magnétisme," and is a valuable working out of the theory of the pressures, initiated by Clerk Maxwell, and further improved by von Helmholtz, Kirchhoff, and other writers. The number closes with an article on ternary substitution-groups of finite order which leave a triangle unchanged, by H. Maschke. This paper is complementary to C. Jordan's "Sur les équations, differentielles linéaires à integrale algébrique," and "Sur la détermination des groupes d'ordre fini contenues dans le groupe linéaire."

Zeitschrift für wissenschaftliche Zoologie, Bd. lix. Heft I.Prof. A. R. von Heider gives a detailed description of a new Actinian (Zoanthus chierchia) obtained during the cruise of the Vettor Pisani. Prof. A. Korotneff describes the embryonic development of Salpa democratica. According to him the follicle-cells do not play the important part in the development of Salpa which Salensky attributed to them, nor do they form a temporary scaffolding for the blastomeres, as stated by Brooks. The embryo is built up of blastomeres in the normal manner, and embryonic layers are present with the same significance as in other groups. The cloaca is formed by the union of endodermal diverticula, and the pericardium develops as an outgrowth of the pharynx.-Prof. W. Schimkewitsch writes upon the structure and development of a species of Dinophilus living in the White Sea, near the Solovetzki laboratory. The twofold affinities of this interesting type, on the one hand with the Annelids, and on the other with the Rotifers, are succinctly stated.--Prof. Vejdovsky writes upon the sexual apparatus of Lumbriculus variegatus. - Dr. Montgomery deals fully with the anatomy of a new type of Nemertine (Stichostemma Eilhardi) discovered in fresh-water aquaria in the Berlin Zoological Institute.-Dr. McKim describes the nephridial funnel apparatus of Hirudo.

\section{SOCIETIES AND ACADEMIES. EDINBURGH.}

Royal Society, March 18.-The Rev. Prof. Flint, VicePresident, in the chair.-Prof. Crum-Brown communicated a paper, by Mr. R. Fairbairn and himself, on the action of sodium mercapticle on dibromomalonic ether.-Prof. J. C. Ewart communicated a paper, by Mr. F. J. Cole and himself on the dorsal branches of the cranial and spinal nerves in elasmobranchs. Dr. Traquair read a paper on phosphorescent sandstones. Prof. Tait read a note on the electromagnetic wave-surface.

April 1.-Sir Douglas Maclagan, President in the chair.-A paper, by the Duke of Argyll, on the glaciation of two glens, was read. The glens are Glenaray and Glenshira. The usual explanation of the phenomena of glaciation as observed in the West Highlands is that the glaciation was caused by an enormous ice-cap covering the whole country. His Grace does not consider that the phenomena can be so explained. Rocks are found which are striated and smoothed on one side, while the other side remains rough. Isolated blocks, without striation, 